years or so following the collapse of the EIS (see figure). Perhaps this delay was a result of transatlantic asymmetry in the

\footnotetext{
1. Fairbanks, R. G. Nature 342, 637-642 (1989).

2. Bard, E., Hamelin, B., Fairbanks, R. G. \& Zindler, A. Nature 345, 405-410 (1990)

3. Edwards, R. L. et al. Science 260, 962-968 (1993)

4. Charles, C. D. \& Fairbanks, R. G. Nature 355, 416-419 (1992).

5. Stocker, T. F. \& Wright, D. G. Nature 351, 729-732 (1991).

6. Lindstrom, D. R. Paleoceanography 5, 207-227 (1990)

7. Lindstrom, D. R. \& MacAyeal, D. R. Science 245, 628-631 (1989).

8. Lehman, S. J. et al. Nature 349, 513-516 (1991).

9. Barnola, J. M. Raynaud, D. Korotkevitch, T. S. \&Lorius, C. Nature 329, 408-413(1987)
}

climate system, a higher tolerance of the LIS to climate warming, or the effects of short-lived cooling perturbations possibly caused by the first meltwater influx (such as Younger Dryas cooling).

\section{Dean R. Lindstrom}

Sullivan East High School,

7677 South Coles,

Chicago, Illinois 60649, USA

Douglas R. MacAyeal

Department of Geophysical Sciences, University of Chicago,

5734 South Ellis Avenue,

Chicago, Illinois 60637, USA

\title{
Recording fires by satellite
}

SIR - Cahoon et al. ${ }^{1}$ illustrate the use of a satellite in mapping grass or forest fires at night. The wavelength band used was 0.4 $-1.1 \mu \mathrm{m}$, which spans the visible and very near infrared part of the spectrum. The illumination of cities was eliminated by their permanence, fires being of short duration. Only photographic prints, and not the basic digital information, were archived. The satellite used was one of the Defense Meteorological Satellite Program (DMSP) Block 5, with an effective resolution of about $2.7 \mathrm{~km}$.

Routine National Oceanic and Atmospheric Administration (NOAA) meteorological satellites seem more suitable in principle for this task, for every part of the Earth is traversed twice every 24 hours, in midday sunshine and at night. The intensity of sunshine is a maximum at $0.5 \mu \mathrm{m}$ (corresponding to a temperature of $6,000 \mathrm{~K}$ ) and the Earth's emission has a maximum at about $11.0 \mu \mathrm{m}(300 \mathrm{~K})$. These two emission spectra cross over with an intensity of about one-fortieth of the maximum at a wavelength of about $4 \mu \mathrm{m}$, the precise values depending on the emission temperatures and other factors. The satellite messages are in archives at the University of Dundee and are generally available.

The NOAA satellites record the scene below them in several wavebands, one of which, channel 3 , is $3.55-3.93 \mu \mathrm{m}$. This is about the maximum strength in the emission spectrum for a temperature of about $700 \mathrm{~K}$, or dull red heat. Flames at $1,200-$ $1,500 \mathrm{~K}$ are about 16 times as intense although in channel 3 the strength is around half the maximum and so they can be 5 or 10 times as strong as red heat. But a flame with an area of only $20 \times 20 \mathrm{~m}$ will outshine $1 \mathrm{~km}^{2}$ of ordinary territory in bright sunshine and will be seen as very bright at night, while urban illumination is
That could easily be remedied if it were required for hotspot surveys; and the resolution (pixel size $1.1 \mathrm{~km}$ at nadir) is much better than DMSP records. However, to record the message at full resolution it would require the receiver to be within the general area being surveyed, for example one station at about the centre of gravity of Africa.

A more satisfactory method for equatorial observation is to use a geostationary satellite; and there is a reasonable prospect that the next Meteosat, above the Equator on the zero meridian, will have a recording channel in the same wavelength band as channel 3 . The message could then be made available everywhere in Europe and Africa at any time of day or night, so it would be possible to make the most of cloud-free periods.

\section{R.S. Scorer}

2 Stanton $R d$,

London SW20 8RL, UK

\section{Cahoon, D. R. et al. Nature 359, 812-815 (1992) . Scorer, R. S. Satellite as Microscope (Ellis Horwood, Chichester. 1990). and the zootype}

SIR - Possession of a specific set of genes involved in pattern formation has been proposed as the character defining the kingdom Animalia (the zootype ${ }^{1}$ ). This concept arises from some remarkable similarities in terms of both structure and expression pattern between key development-regulating genes in relatively 'advanced' metazoans, specifically Drosophila and vertebrates. Comparative data for 'primitive' metazoans are required to validate the zootype concept and, as the most primitive metazoans with tissue-level organization, cnidarians are potentially one of the most informative 'lower' metazoan phyla. Here we demonstrate that even-skipped and Antennapedia class homeobox genes are adjacent in the genome of the coral Acropora formosa. This linkage in a cnidarian, observed also in vertebrates ${ }^{2,3}$ ( $a$ in the figure), suggests first that this is likely to be the ancestral arrangement of these genes; and second that the 'primitive' function of even-skipped class genes is in posterior pattern formation.

We have isolated a single $A$. formosa genomic clone containing a pair of homeobox genes. Subclones derived from one end of this genomic clone encode a homeodomain belonging to the evenskipped (eve) class ${ }^{4}$. The similarity between the predicted amino-acid sequence of the cnidarian eve-like homeodomain and its insect and vertebrate equivalents is, remarkably, approximately 77-80 per cent ( $b$ in the figure), showing that this class of genes was distinct very early in 